UCRL-ID-149076

\title{
Secure, Transportable, Autonomous Reactor (Star) Concept
}

C.K. Chou, C.F. Smith, N.W. Brown, J.A. Hassberger, and W.G. Halsey

\section{July 1, 2002}

Lawrence

Livermore

National

Laboratory

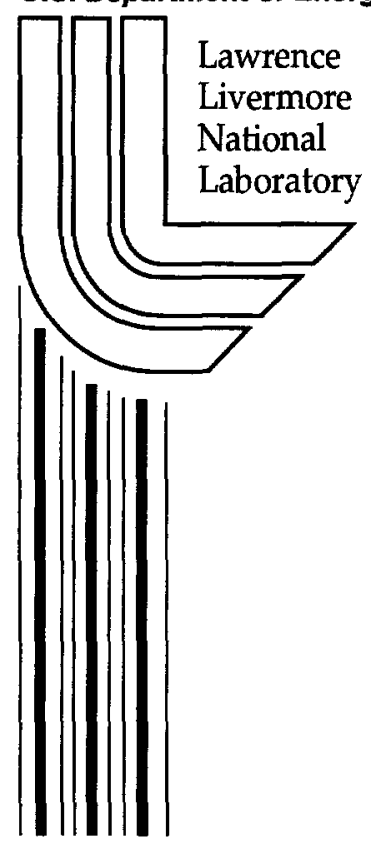




\section{DISCLAIMER}

This document was prepared as an account of work sponsored by an agency of the United States Government. Neither the United States Government nor the University of California nor any of their employees, makes any warranty, express or implied, or assumes any legal liability or responsibility for the accuracy, completeness, or usefulness of any information, apparatus, product, or process disclosed, or represents that its use would not infringe privately owned rights. Reference herein to any specific commercial product, process, or service by trade name, trademark, manufacturer, or otherwise, does not necessarily constitute or imply its endorsement, recommendation, or favoring by the United States Government or the University of California. The views and opinions of authors expressed herein do not necessarily state or reflect those of the United States Government or the University of California, and shall not be used for advertising or product endorsement purposes.

This work was performed under the auspices of the U.S. Department of Energy by the University of California, Lawrence Livermore National Laboratory under Contract No. W-7405-Eng-48.

This report has been reproduced directly from the best available copy.

Available electronically at http://www.doc.gov/bridge

Available for a processing fee to U.S. Department of Energy And its contractors in paper from

U.S. Department of Energy

Office of Scientific and Technical Information

$$
\text { P.O. Box } 62
$$

Oak Ridge, TN 37831-0062

Telephone: (865) 576-8401

Facsimile: (865) 576-5728

E-mail: reports@adonis.osti.gov

Available for the sale to the public from

U.S. Department of Commerce

National Technical Information Service 5285 Port Royal Road

Springfield, VA 22161

Telephone: (800) 553-6847

Facsimile: (703) 605-6900

E-mail: orders@ntis.fedworld.gov

Online ordering: http://www.ntis.gov/ordering.htm

\section{OR}

Lawrence Livermore National Laboratory

Technical Information Department's Digital Library

http://www.llnl.gov/tid/Library.html 


\title{
Secure, Transportable, Autonomous Reactor (STAR) Concept
}

\author{
C. K. Chou, Craig F. Smith, Neil W. Brown, James A. Hassberger, William G. Halsey \\ Energy and Environment Directorate \\ Lawrence Livermore National Laboratory (LLNL) \\ Telephone: 925-422-4950 Fax: 925-422-0096 email: chou1@LLNL.gov
}

The Secure, Transportable, Autonomous Reactor (STAR), is a concept for a small, highly proliferation resistant, sealed-core nuclear power system with unique design features that make it appropriate for a variety of applications.

STAR features include:

- Long lifetime sealed core installed at construction

- 10 to 30 year core life, depending on design and size

- No capability for on-site refueling, no user access to the fuel, no need for user to have fuel cycle technology

- Reactor transported intact to the user site

- Reactor core is replaced by vendor at end of life, spent fuel returns intact to supplier

- Useable in remote areas for local power

- Modular design for factory production to minimize cost

- Simple operation with reliance on autonomous control and remote monitoring

- Robust, simple design with inherent safety features, high reliability and reduced maintenance

These features permit STAR to address a variety of potential applications, including:

- Deployment in developing countries with limited infrastructure

- Remote/isolated location deployment (islands, oil fields, military installations, etc.)

- Central generation on small electric grids

- Multi-unit central station use or distributed generation on large electric grids

- Alternative energy products (process heat, space heat, fresh water, hydrogen, etc.) in addition to electricity

The current STAR concept builds on earlier work ${ }^{1,2,3}$ that investigated the features required for implementation of such a system and evaluated a variety of reactor types. These prior evaluations considered water cooled, gas cooled, liquid metal cooled and molten salt reactors, both thermal and fast spectrum in a variety of sizes. To meet the long core life, transportability, simplicity and safety objectives, a small liquid metal cooled fast spectrum reactor has been chosen as the most promising. A fast spectrum reactor can achieve very long core life with a balance of fissile and fertile material. Use of a fast neutron spectrum could also allow for effective consumption of excess weapon useable fissile material, if this application is needed. The small active core, modest energy density and the thermal properties of liquid metal coolant facilitate designing inherent and passive safety features into the system to mitigate all credible conditions. Such small nuclear systems can be kept simple and virtually autonomous with minimal maintenance. The user primarily operates the non-nuclear portion of the plant and just monitors the nuclear system. With simple operation, minimal maintenance, inherent safety and no refueling, the operating staff and costs are minimized. Factory mass production can reduce capital cost. The user does not need nuclear fuel fabrication or spent fuel management 
infrastructure. System economics may be controlled by the up front fuel costs, but modest fuel cost is a strong point for nuclear energy economics.

STAR design covers a range of output and lifetime, traded against transportation weight. The nominal design is sized in the range of 50 to $150 \mathrm{Mwe}$, with larger demand accommodated through installation of multiple units. More compact designs as small as $10 \mathrm{Mwe}$ are possible for special applications. The larger size could be delivered by ship or barge, small systems could be transported by rail or heavy surface transport.

Proliferation resistance is enhanced by several features of the STAR concept. The reactor supplier (from an advanced nuclear technology nation - US, France, Russia, etc.) would be responsible to the international community for proliferation safeguards in the entire fuel cycle, rather than the user. Implementing this concept will require development of a mechanism for "Safeguards Transparency Certification" from an international body such as a "Nuclear Suppliers Organization'. This relieves the reactor user of much of the burden of international scrutiny. The user would not require extensive infrastructure and nuclear expertise, and would not have access to the fuel or fuel cycle facilities. Material diversion would require diversion and disassembly of the entire reactor and would be time consuming and easily detected. Clandestine material production would be precluded by lack of user access to the core. This safeguards concept is similar to the safety certification of advanced jet airliners by a limited number of high tech suppliers, that are then used by airlines all over the world with pilots that only need to know how to fly them, not build them. Acceptance of this safeguards approach by the international community would further reduce operating cost to the user, with the supplier picking up much of the responsibility.

STAR is fully consistent with the "Joint Study on Enhancing the Proliferation Resistance of Nuclear Technologies" where U.S. DOE and Russian Minatom agreed that small, transportable, sealed-core reactors, are a technology with potential to reduce proliferation risk in the future

A survey ${ }^{4}$ completed by the International Atomic Energy Agency (IAEA) indicated the need for such systems and that by the year 2015, developing countries are expected to need 70-80 small and medium sized reactor systems. In the U.S., nuclear operating companies have expressed interest in several types of small modular reactors that can be built with moderate investment risk compared to large reactors, and deployed in multiple units to meet demand. Currently, other countries are developing small reactors for this potential commercial market, but these efforts tend to focus on the development of the reactor without integrated considerations of the overall fuel cycle, proliferation or waste issues. It is important for the next generation of reactors to meet to U.S. global non-proliferation objectives, and for the U.S. to regain its historical technology leadership in nuclear energy.

The development of STAR systems can greatly enhance the saftey, safeguards and international transparency features of nuclear plants. But successful fabrication of STAR systems requires the development of very long-lived cores; innovations in fuel, cladding, and structural materials; advances in control and reactivity-compensating materials; and development of new techniques and models for the prediction of materials behavior and design performance. STAR development necessitates not only an integrated set of technical R\&D activities, but also international participation. A STAR development project is envisioned to consist of three phases leading to a preliminary system design in five years. In the first phase (lasting approximately 18 months), detailed system requirements will be developed; feasibility issues will be identified and 
addressed; and a technology down-selection to one or two candidate reactor systems will be performed. In the second phase (also lasting approximately 18 months), the technology research and development program needed to perform a final conceptual design will be identified and implemented. In phase 3 (lasting approximately 2 years), the conceptual design will be completed. At the end of the five-year program, all the necessary data will have been generated for initiation of detailed design and development of a prototype.

\section{References}

${ }^{1}$ Brown, N.W., Elias, E., Greenspan, E., Hassberger, J. A., "Proliferation Resistant Fission Energy Systems", International Conference on Future Nuclear Systems, Global '97, Yokohoma Japan, October 5-10, 1997

${ }^{2}$ Brown, N. W., Hassberger, J. A., "New concept of small power reactor without on-site refueling for non-proliferation." Lawrence Livermore National Laboratory, UCRL-JC-131317. Presented at International Atomic Energy Agency Advisory Group Meeting on Propulsion Reactor Technologies for Civilian Applications, Obninsk, Russia,July 20-24, 1998.

${ }^{3}$ Smith, C. F., Brown, N. W., Hassberger, J. A., "The Secure, Transportable, Autonomous Reactor (STAR): A Small, Proliferation-Resistant Reactor System for Developing Countries" Lawrence Livermore National Laboratory, UCRL-JC-133319. Presented at the ProliferationResistant Nuclear Power Systems Workshop, Livermore, California, June 2-4, 1999.

${ }^{4}$ IAEA, "Introduction of Small and Medium Reactors in Developing Countries", Proceedings of two IAEA Advisory Group meetings held in Rabat, Morocco, 23-27 October 1995 and Tunis, Tunisia, 3-6 September 1996.

For further information, contact: C.K. Chou, Craig Smith or Bill Halsey Lawrence Livermore National Laboratory Energy and Environment Directorate 